\title{
RADIOLOGY DIAGNOSTICS OF THE CONSEQUENCES OF VASELINE OIL INTRODUCTION INTO SOFT TISSUES AT THE STAGES OF SURGICAL TREATMENT
}

\author{
Yulia A. Stepanova, Nora E. Arutyunyan*, \\ Naida O. Sultanova, Aleksey A. Kopyltsov, Dmitry V. Kalinin
}

\author{
A.V. Vishnevsky National Medical Research Center of Surgery, Moscow, Russia
}

\begin{abstract}
Introduction. Over the past 30 years, minimally invasive methods of aesthetic medicine have become increasingly well-known in the world. Dermal fillers are among the most popular aesthetic procedures because they carry immediate results, very few risks and little recovery time. Despite the regulations governing the provision of aesthetic non-surgical medical services, the number of patients affected by the augmentation of vaseline oil into soft tissues to correct the shape of organs and soft tissues has increased. Nowadays, soft-tissue augmentation with large amounts of any foreign material and these types of procedures has been abandoned by health professionals and plastic surgeons all over the world. The administration of small doses (from $1 \mathrm{ml}$ to $5 \mathrm{ml}$ ) of injectable preparations, mainly absorbed within 2-12 months, is permitted and widely used to correct minor contour of the face, wrinkles and soft tissues. Objective: development of an algorithm for radiological examination of patients at the stages of surgical correction of the consequences of the augmentation with vaseline oil into soft tissues for aesthetic purposes. Materials and methods. In a retrospective study, the results of the examination and surgical treatment of 17 women were evaluated. The patients were treated at various times with the consequences of the augmentation with vaseline oil in mammary glands, buttocks and shins. There were 11 (64.7\%) patients with vaseline oil introduced into one region, into two regions- 5 (29.4\%), and one woman 1 (5.9\%) into three regions. The migration of vaseline oil to adjacent anatomical areas was observed in 13 out of 17 (76.5\%) patients. All patients underwent ultrasound, MSCT, and/or MRI at the stages of surgical treatment. Results. Multiple-stages (from 1 to 8) surgical treatment was performed and in addition to excision of tissues affected by fibrosis and oleogranulomas, also reconstructive surgeries to restore the volume and contours of the organs were performed. Overall, 51 surgical interventions were performed. MSCT and MRI studies can identify oleogranulomas and determine the volume of soft tissue damage. If it is possible to choose the method of radiological investigation, preference should be given to MRI. The MR Imaging is carried out without radiation exposure and the introduction of a contrast agent and allows you to determine the full volume of soft tissue damage, as well as the presence of fibrous tissue, in the mode without fat suppression. Ultrasound is the easiest to perform, however, an effective method for diagnosing complications after soft tissues augmentation. And it is effective when searching for individual fat fragments during surgery and evaluating the intervention area around the perimeter. In the postoperative period, the ultrasound revealed limited fluid accumulations ranging in size from 12 to $36 \times 47 \mathrm{~mm}$. In 11 cases, the clusters regressed independently during ultrasound monitoring, and in 6 cases, it was considered appropriate to evacuate the contents under ultrasound control. Good and satisfactory results were obtained in 6 patients (MRI data and visual effect), and interventions, mainly of a reconstructive nature, are expected in 11 patients. Conclusion. The difficulties and multi-stage surgical treatment in patients after soft tissue augmentation with vaseline oil are associated with a large volume of tissue damage with a violation of their trophic function, the migration of vaseline oil to adjacent anatomical areas, the inability to eliminate the lesion and simultaneous reconstruction. MRI makes it possible to determine the extent of the lesion at all stages of surgical treatment, ultrasound is an important pre / intraoperative navigation during surgical treatment, and also allows postoperative management of patients.
\end{abstract}

Key words: Vaseline oil, oleogranuloma, vaseline oil migration, fibrous tissue, breast reconstruction

\section{INTRODUCTION}

One of the most frequent minimally invasive interventions in aesthetic medicine is contour injection by fillers. The history of the use of substances for facial contouring Injections is about 130 years old. At the dawn of modern aesthetic medicine, paraffin, fat grafts and silicone, petroleum jelly was used for procedures. However, the safety and effectiveness of such interventions was unsatisfactory. In the second half of the last century, the first fillers were based on bovine collagen. (Zyderm, Zyplast) [1]. Since then, a large number of fillers have been developed and used: based on fibrillated Teflon; collagen derivatives, including human; biopolymers and composite materials; fillers based on hydroxyapatite and fibrin polymers of lactic acid (Poly-L-Lactic Acid - PLLA) [2]. Despite the wide and safe choice of material for augmentation in aesthetic surgery, today complications are recorded after augmentation of vaseline oil into the tissues.

As a medical procedure, introduction of vaseline oil into soft tissues was first described in 1899 by the Austrian surgeon Robert Gersuni, who injected paraffin into the scrotum of a young man at the site of a removed testicle as a testicular prosthesis. Since then, vaseline oil injections have been used for a wide range of cosmetic procedures: filling clefts of the soft palate, wrinkles, facial deformities, as well as for

*noranoranora5@mail.ru 
muscle, breast and penile enlargement. However, seven years later, in 1906, M.L. Headingsfeld presented the first report on the adverse effects of oil injection [3]. Injections of vaseline oil and other similar substances in most cases causes complications, including deformation of organs and skin, the formation of olegranulomas and necrosis [4]. There is also no definitive consensus on a causal relationship between the administration of various fillers and carcinogenesis. It is believed that the first report on the occurrence of tumors after the introduction of mineral oil was made by French doctors in 1917. However, this message in the literature could only be found in the form of a mention in later sources [5]. Studies by Japanese scientists have shown that the period from breast augmentation for example, to the diagnosis of breast cancer ranged from 4 months to 50 years [6]. This can be explained both by chronic inflammation and by the cancer itself, taking into account the length of observation. Thus, although there are reports of cancer after augmentation of vaseline oil into soft tissues and causal relationships between foreign bodies and carcinogenesis have been studied, a final consensus on this issue has not yet been formed [7-11].

Despite the regulations governing the provision of aesthetic non-surgical medical services, the number of patients affected by the augmentation of vaseline oil into soft tissues to correct the shape of organs and soft tissues has increased. Nowadays, soft-tissue augmentation with large amounts of any foreign material and these types of procedures has been abandoned by health professionals and plastic surgeons all over the world. The administration of small doses (from 1 to $5 \mathrm{ml}$ ) of injectable preparations, mainly absorbed within 2-12 months, is permitted and widely used to correct minor contour of the face, wrinkles and soft tissues [3, 4, 12-14].

\section{AIM}

The aim is to develop the algorithm for radiological examination of patients at the stages of surgical correction of the consequences of the augmentation with vaseline oil into soft tissues for aesthetic purposes.

\section{MATERIALS AND METHODS}

In a retrospective study, the results of the examination and surgical treatment of 17 women were evaluated. The patients were treated at various times with the consequences of the augmentation with vaseline oil in mammary glands, buttocks and shins. There were $11(64.7 \%)$ patients with vaseline oil introduced into one region, into two regions: 5 (29.4\%), and one woman 1 (5.9\%) into three regions.

Only 4 out of 17 patients knew the volume of injected vaseline oil, which ranged from 200 to $2200 \mathrm{ml}$. The migration of vaseline oil to adjacent anatomical areas was observed in 13 out of 17 (76.5\%) patients. All patients underwent ultrasound, MSCT, and/or MRI at the stages of surgical treatment

\section{RESULTS}

Clinical sings of complications after oil injections had begun from 1 month to 4 years. Patients had sought treatment from 6 months to 2 years after clinical presentation.

Oleogranuloma (geleoma) is the most common complication of vaseline injection. Oil migration in the contiguous tissues is presented in 13 of $17(76.5 \%)$ patients. Localized oleogranuloma is presented in $4(23.5 \%)$ patients.

The great majority of oleogranulemas had specific ultrasound features such as thick hyperechogenic capsule, irregular shaped, heterogeneous hypoechogenic structure (so-called cystic type, Fig. 1 a,c). Cystic-solid (mixed type) or solid structure was less common, solid-type granulomas rarely contained calcified focuses (sclerous type, Fig. 1 b,c). Boundaries of damaged tissues are irregular, poorly defined. True borders detection of oil spreading was challenging in some cases, because there were impossible to distinguish between the sclerous type geleoma and fibrotic changed tissues provoked by low blood supply.
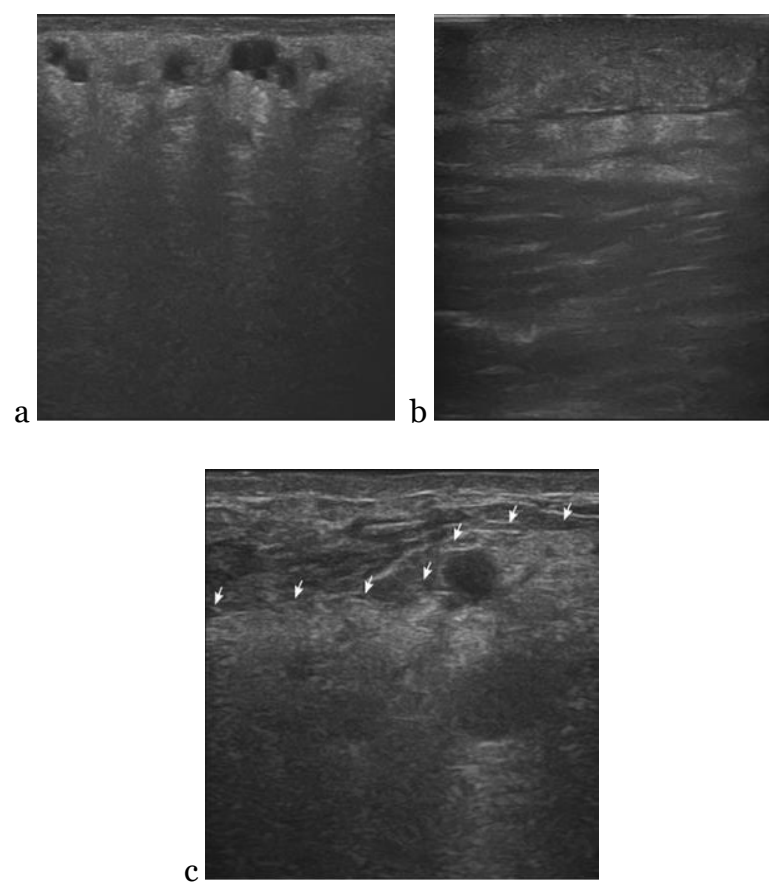

Figure 1. Ultrasound images of various options for the defeat of subcutaneous fat: a - anechogenic geleomas; $b$ - infiltrative ("drain") tissue damage; c - combination of tissue and geloma infiltration (indicated by arrows)

Oleogranulomas were almost heterogeneous and isodensive to surrounded soft tissues on CT scan native phase, also contained multiply fat foci (Fig. 2). There were no abnormal contrast enhancements of these foci.

On MRI, oleogranulomas were defined as zones of non-uniform iso-intensive along with soft tissues on both T1- and T2 WI, with moderate non-uniform enhancement after the administration of a contrast agent. Within these zones, multiple well-defined foci were identified, which had a high MR signal on T1 WI and intermediate on T2 WI (Fig. 3), which became 
hypointense after the application of fat suppression, which was histologically consistent with the fat component. During MRI, the volume and boundaries of the lesion were clearly defined, which was undoubtedly important, given the tendency of vaseline oil to migrate in soft tissues. The most effective assessment of the volume and prevalence of oil was possible with $3 \mathrm{D}$ reconstruction of the MR image. Also, MRI made it possible to locally identify areas of inflammation and infection.
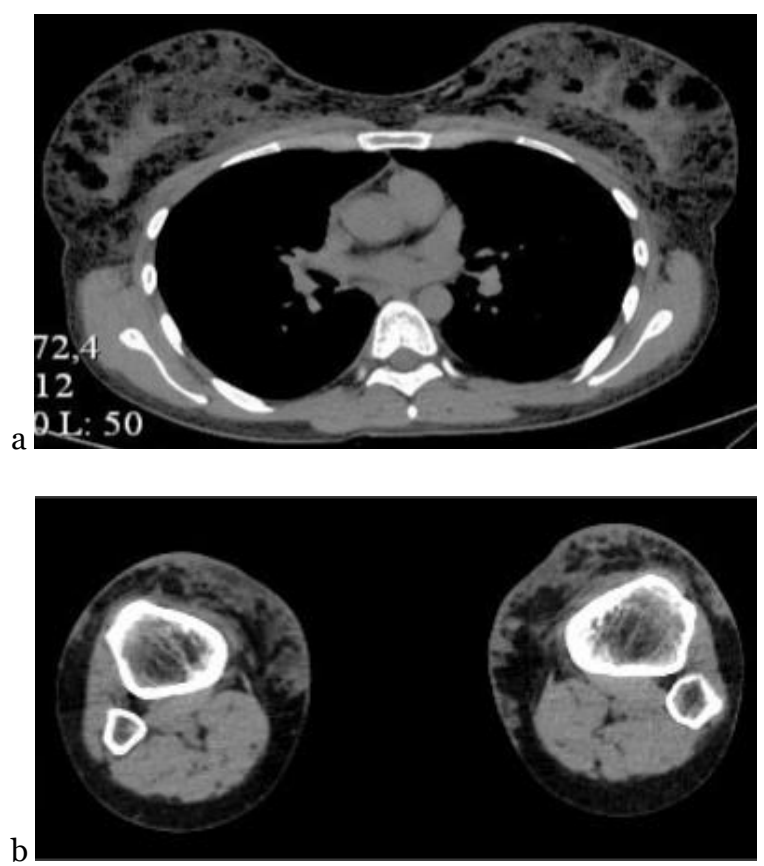

Figure 2. MSCT images, native phase: a - total lesion of breast tissue by fibrosis, visible oleogranulomas of various sizes; b - in the altered tissues of the medial surface of both legs, areas of liquid density (heleomas) surrounded by fibrous tissue are determined

There was found out gradual growing of oleogranulomas during the follow-up period, which became more solid, flew together into a single conglomerate; the color of the skin over the injected area was changed later, which became yellow, light brown, or dark brown color, sometimes with purple blotches (Fig. 4). After 2 month after the skin color changes in $2(11.7 \%)$ of 17 patients vaseline plates were developed with forming trophic ulcers afterwards.

Pain in granulomas was rather common. There were also spreading of vaseline oil and trophic ulcers formation both in the injection zone and in the zone of oil spreading. Oil spreading in tissues was not only in the distal direction due to static action, but also in the proximal direction, laterally and medially, as well as in any direction by the lymphatic system. In 2 patients after the oil injection into the gluteal muscles, there was oil spreading to lumbosacral region, in 1 patient right up to ThXII vertebra.

During the primary medical aid in patients with multifocal soft tissue damage, the main task is to determine the primary "hot" focus. In some cases, patients suffer from their state of mind more - the main complaints are changes in one area, for example, in the mammary glands, while the leading surgical complications are in gluteus muscles or legs. Therefore, despite the patient's main complaints, it is better to start surgical treatment of the most "showy" damaged area, which is determined by the data of radiological diagnostics at each stage of treatment (if there is more than one).
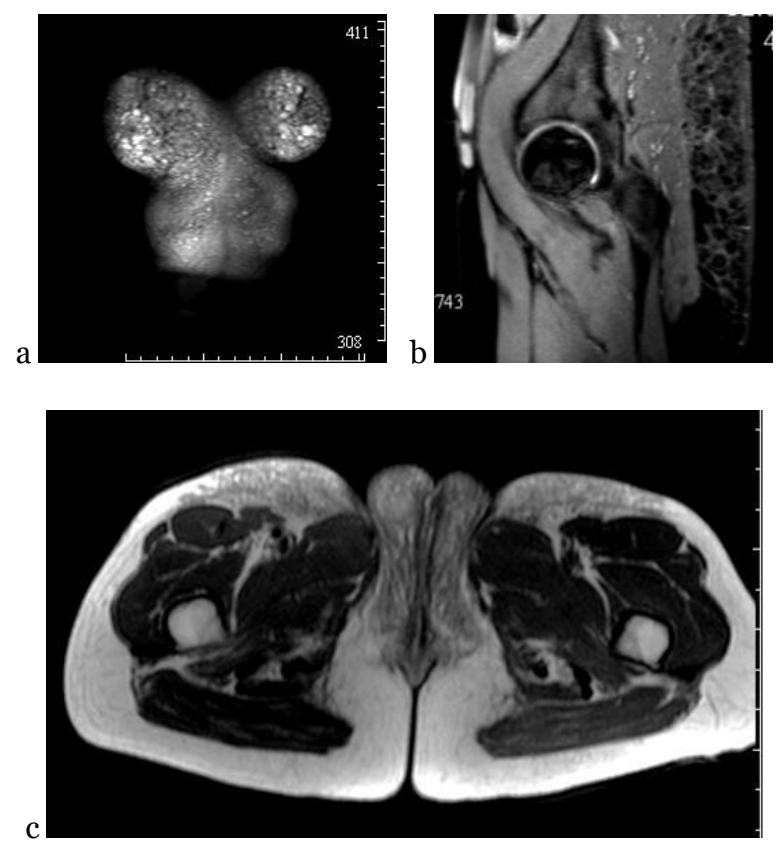

Figure 3. MR images of soft tissues: a - the anterior surface of the chest and abdominal walls, T1 WI.; b - gluteal region with extension to the superficial parts of the gluteus maximus muscles, T2 WI; c - in the inner and surface of the thighs, external genital organs, in T1 WI
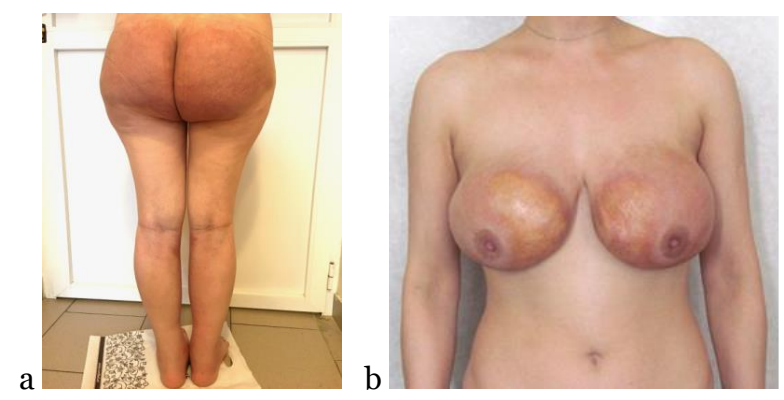

Figure 4. Clinical manifestations of introduction of vaseline oil: a - the mammary glands of the patient are represented by single conglomerates of oleogranuli on both sides with

changes in the skin; b- the buttocks of the patient represented

by introduced of vaseline oil with the changes in the skin

In the study, the patients were operated on in 1-8 stages (Fig. 5). At the same time, treatment was considered completed only in $6(35.3 \%)$ of 17 patients (MRI data and visual effect), who were operated on in 1-7 surgical stages (on average -3 surgical stages). 8 patients were treated and operated on by us in one surgical stage (of them, only 1 patient completed the treatment - a bilateral subcutaneous mastectomy was performed, she refused to reconstruct the mammary glands). 9 patients were treated in 3-4 surgical stages and 5 patients in 5-8 surgical stages. 

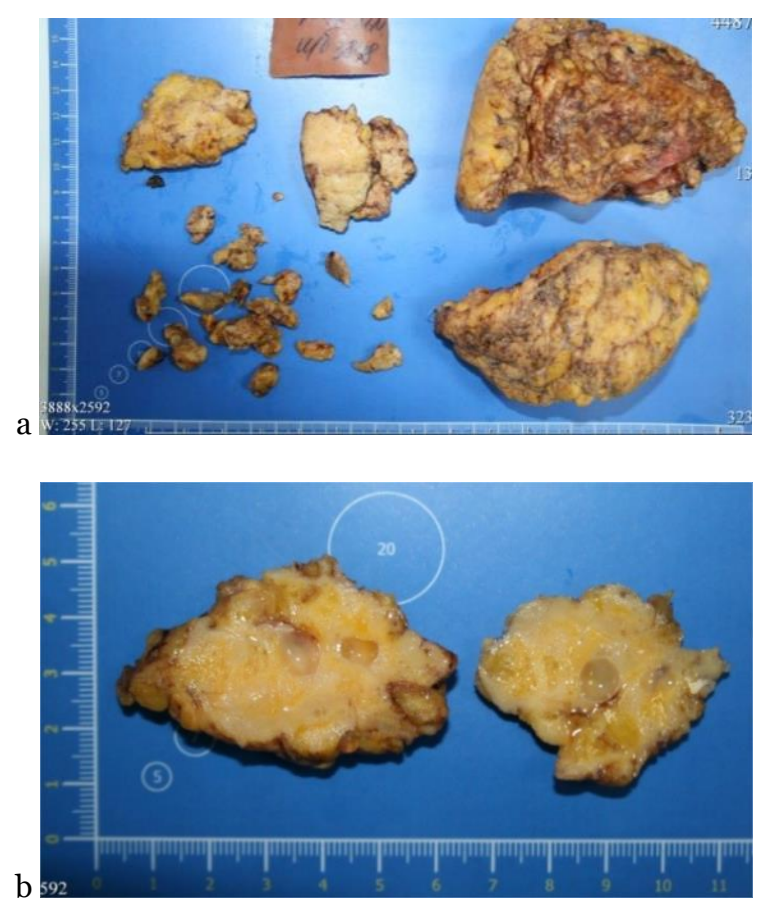

Figure 5. Remote conglomerates of fibrous tissue: a - general view, $\mathrm{b}$ - in section, different diameters cavities containing vaseline oil
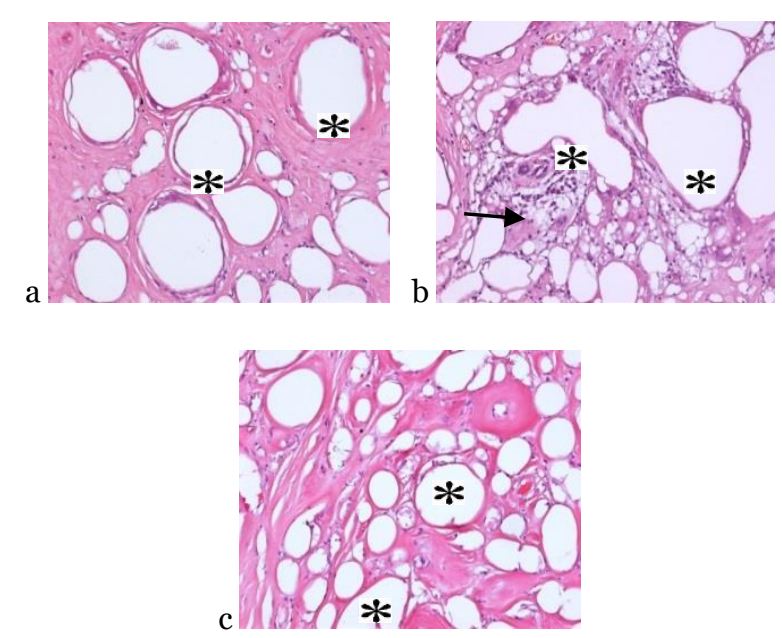

Figure 6. Microscopic examination of soft tissues,

Hematoxylin and eosin, increase 200: a - massive "fields" of fibrosis with the presence in the thickness of xanthoma cells and individual drops of vaseline oil ( ), surrounded by giant multinuclear cells of the "foreign body" type, single

lymphocytes, xanthoma cells; $b$ - along the periphery of intact ducts of the mammary gland (arrow) with pronounced atrophy, focal inflammatory infiltration from lymphocytes, macrophages, plasma cells; on the periphery of their drops of vaseline oil , surrounded by giant multinucleated cells of the

type of "foreign bodies", lymphocytes, xanthoma cells;

$\mathrm{c}$ - severe fibrosclerosis and hyalinosis of the stroma of the

mammary gland after the introduction of vaseline oil

During the histological examination of the operating material in all the above clinical observations, a local inflammatory reaction of varying severity occurs in the form of focal and diffuse infiltration of soft tissues by segmented leukocytes, lymphocytes, macrophages, histiocytes. The presence of foci of fibrosis of varying severity with the presence of many cavities without epithelial lining, filled with vaseline oil, was also noted: from small to wide fields of merging different-sized ones. On the periphery of most of the cavities, xanthoma cells and giant multinucleated cells of the "foreign body" type are installed (Fig. 6). Some patients had focal and diffuse infiltrates with a large number of eosinophilic leukocytes.

It should be noted that ultrasound is an important pre/intraoperative navigation during surgical treatment, and also allows postoperative management of patients.

According to the preoperative ultrasound, the compaction of soft tissues was determined 3-5 cm wider than the "Vaseline track". In fact, intraoperatively, there was a slightly different picture. Severe fibrosis along the width of the "track", moderate fibrosis 3-6 cm around ("visible" by ultrasound) and gentle (visible only "by eye"), incipient fibrosis of the subcutaneous tissue by $3.0-5.0 \mathrm{~cm}$ or more around. This tactic makes it possible to avoid residual oleoganulomas.

The treatment was not completed in 11 (64.7\%) patients who are planning reconstructive stages of surgical treatment.

Expanding the possibilities of fibrous lesions and performing tissue resection is sometimes forced by the level of fibrosis, healing of a postoperative wound is much longer. In the postoperative period, ultrasound examination revealed limited fluid accumulations ranging in size from $12 \mathrm{~mm}$ in diameter to $36 \times 47 \mathrm{~mm}$, which usually regressed with dynamic monitoring. The evacuation of the contents under ultrasound control was considered expedient only in 6 cases.

\section{DisCussion}

Vaseline injections occurs significant failure of microvascular blood supply and lymphatic drainage, which provokes cells and tissues inflammatory response pathway. The outcome of pathological changes is the development of foci of hyalinosis - the deposition of translucent dense masses of hyaline, reminded cartilage tissue. All pathological reactions are cyclically repeated, failure of microvascular blood supply and lymphatic drainage affect not only the injected area, but also the surrounding tissues. Thus, the mechanism of an autonomous self-sustaining granulomatous process is triggered. Oleogranuloma is a local destruction of adipose tissue, which is based on an inflammatory process that occurs because of trauma, surgery approach, and persistence of the foreign body in tissues [15]. The injected gel is found as dense cicatricial-gel conglomerates with relatively clear boundaries; loose, encapsulated, relatively large masses; diffuse tissue impregnation $[16,17]$. There were different combinations of these forms in the most cases.

Pathological changes that occur after the injection of oily substances are characterized by the presence of acute purulent inflammation, followed by a typical granulomatous reaction. In the future, the described lesion is replaced by fibrous inflammatory tissue. In 
Yu. A. Stepanova et al., Consequences of vaseline oil introduction..., RAD Conf. Proc., vol. 5, 2021, 119-124

most cases, the lesion is accompanied by regional lymphadenitis. The removed oleogranulomas contain many inflammatory cells, including giant cells, neutrophils, lymphocytes, and macrophages [18].

The consequences of the soft tissues augmentation by vaseline oil are fraught with the development of formidable complications due to the presence of a large mass of foreign material, a large area of damage, and probable infection, which can lead to the loss of an organ, limb, or even to a life-threatening condition, generalization of infection.

Surgical treatment in this category of patients is multi-staging and long-term. The mail goal for surgeons is to remove the damaged tissue, heal the wound and discharge the patient from the hospital. The reason of multi-staging surgical treatment is not only because of wide spreading of lesions in the injected area, but also because of presence of vaseline oil in another anatomical zone and its migration to surrounding anatomical areas.

Moreover, because of the wide excision of largevolume solid fibrous tissue conglomerates containing oleogranulomas, one-stage reconstruction - filling the lack of volume - is not always possible. Therefore, during the treatment of this complex category of patients, it is necessary not only to of remove the affected tissues, but to think over the options and methods for the subsequent reconstruction of the contours and volume of the operated area.

Ultrasound is the most effective diagnostic method for injection correction of soft tissues with vaseline oil. Ultrasound is effective in searching for individual fat fragments during surgery and assessing the intervention area around the perimeter Also, ultrasound allows to effectively monitor the condition of patients in the postoperative period and timely carry out minimally invasive correction under ultrasound control.

MSCT and MRI studies make it possible to clearly identify oleogranulomas and determine the extent of soft tissue lesions. If there is a choice of examination method, preference should be given to MRI. The examination is carried out without radiation exposure and the introduction of a contrast agent, and allows, in a mode with fat suppression, to determine the total volume of soft tissue lesions, and also determines the presence of fibrous tissue.

In general, our approach coincides with the literature data [19-23]. However, we would like to focus on the wider use of ultrasound at all stages of treatment, which makes it possible to provide effective assistance to patients with a decrease in financial costs in the postoperative period as a result of more rational patient management and a reduction in bed-days.

\section{CONCLUSION}

The most effective methods for diagnosing complications after oil vaseline injections into soft tissues are ultrasound and MR-mammography, which provide all diagnostic information without radiation exposure, sufficient for assessment of the situation and determine the treatment tactics at its stages.

\section{REFERENCES}

1. A.W. Klein, M.L. Elson, "The History of Substances for Soft Tissue Augmentation”, Dermatologic Surgery, vol. 26, no. 12, pp. 1096-1105, 2000. https://doi.org/10.1046/j.1524-4725.2000.00512.x

2. R. Gersuny, "Ueber eine subcutane prothese", Zeitschr Heilkunde Wien u Leipzig, vol. 21, sei. 199-201, 1900. (R. Gersuny, "Concerning a subcutaneous prosthesis", Heilkunde Vienna and Leipzig Journal, vol. 21, pp. 199-201, 1900)

3. M. L. Hedingsfeld, "Histopathology of paraffin prosthesis", J. Cutan. Dis., vol. 24, pp. 513-521, 1906.

4. W. Peters, V. Fornasier, "Complications from injectable materials used for breast augmentation", Can. J. Plast. Surg., vol. 17, no. 3, pp. 89-96, 2009. https://doi.org/10.1177/229255030901700305

5. J. Steffens et al., "Paraffinoma of the external genitalia after autoinjection of Vaseline", Eur. Urol., vol. 38, no. 6, pp. 778-781, 2000 . https://doi.org/10.1159/000020379

6. Y. Tanaka, I. Morishima, K. Kikuchi, "Invasive micropapillary carcinomas arising 42 years after augmentation mammoplasty: A case report and literature review”, World J. Surg. Oncol., vol. 14, no. 6, article no. 33, 2008. https://doi.org/10.1186/1477-7819-6-33

7. H. Bryant, P. Brasher, "Breast implant and breast cancer - reanalysis of a linkage study", N. Engl. J. Med., vol. 332, pp. 1535-1539, 1995. https://doi.org/10.1056/NEJM199506083322302

8. L.A. Brinton, S.L. Brown, "Breast implants and cancer", J. Natl. Can. Inst., vol. 89, no. 18, pp. 1341-1349, 1997. https://doi.org/10.1093/jnci/89.18.1341

9. K.A. Skinner et al., "Breast cancer after augmentation mammoplasty", Ann. Surg, Oncol., vol. 8, pp. 138-144, 2001. https://doi.org/10.1007/s10434-001-0138-x

10. S.A. Mclntosh, K. Horgan, "Breast cancer following augmentation mammoplasty - a review of its impact on prognosis and management", J. Plast. Reconstr. Aesthet. Surg., vol. 60, no. 10, pp. 1127-1135, 2007. https://doi.org/10.1016/j.bjps.2007.03.017

11. D.M. Deapen, E.M. Hirsch, G.S. Brody, "Cancer risk among Los Angeles women with cosmetic breast implants", Plast. Reconstr. Surg., vol. 119, no. 7, pp. 1987-1992, 2007. https://doi.org/10.1097/01.prs.0000260582.23971.02

12. H.F. Smetana, W. Bernhard, "Sclerosing lipogranuloma”, Arch. Path., vol. 50, pp. 296-325, 1950 .

13. V.D. Newcomer, J.H. Graham, R.R. Schafert, L. Kaplan, "Sclerosing lipogranuloma resulting from exogenous lipids", AMA Arch. Derm., vol. 73, no. 4, pp. 361-372, 1956.

https://doi.org/10.1001/archderm.1956.015500400550 $\underline{\mathrm{o} 8}$

14. G. Foxton, C. Vinciullo, C.P. Tait, R. Sinniah, "Sclerosing lipogranuloma of the penis", Australasian J. Dermatol., vol. 52, no. 3, pp. e12-e14, 2011. https://doi.org/10.1111/j.1440-0960.2010.00665.x

15. Е.П. Фисенко, "Инструментальная диагностика осложнений контурной пластики тела гелевыми имплантатами”, докторская диссертация, Российской Академии медицинских наук, Российский научный центр хирургии им. академика Б.В. Петровского, Москва, Россия, 2009.

(E.P. Fisenko, "Instrumental diagnostics of complications of body contouring with gel implants", Ph.D. dissertation, Russian Academy of Medical Sciences, Russian Scientific Center of Surgery named after A.I. Academician B.V. Petrovsky, Moscow, Russia, 2009.)

16. R.E. Barlow, W.E. Torres, P.J. Sones Jr., A. Someren, "Sonographic demonstration of migrating silicone", $\mathrm{Am}$. 
Yu. A. Stepanova et al., Consequences of vaseline oil introduction..., RAD Conf. Proc., vol. 5, 2021, 119-124

J. Roentgenol., vol. 135, no. 1, pp. 170-171, 1980.

https://doi.org/10.2214/ajr.135.1.170

17. N.B. Khedher et al., "Imaging findings of breast augmentation with injected hydrophilic polyacrylamide gel: patient reports and literature review". Eur. J. Radiol., vol. 78, no. 1, pp. 104-211, 2011.

https://doi.org/10.1016/j.ejrad.2009.09.021

18. P. Nyirády et al., "Treatment and outcome of vaselineinduced sclerosing lipogranuloma of the penis", Urology, vol. 71, no. 6, pp. 1132-1137, 2008. https://doi.org/10.1016/j.urology.2007.12.081

19. Q. Qiao et al., "Management for postoperative complications of breast augmentation by injected polyacrylamide hydrogel”, Aesth. Plast. Surg., vol. 29, no. 3, pp. 156-161, May-Jun 2005. https://doi.org/10.1007/s00266-004-0099-0

20. N.B. Khedher et al., "Imaging findings of breast augmentation with injected hydrophilic polyacrylamide gel: Patient reports and literature review", Eur. J. Radiol., vol. 78, no. 1, pp. 104-111, 2011. https://doi.org/10.1016/j.ejrad.2009.09.021
21. Ю.А. Степанова, В.И. Шаробаро, И.П. Колганова, “Лучевая диагностика и лечение осложнений инъекционной контурной пластики молочных желез”, Хирургия. Журн. им. Н. И. Пирогова, № 4 c. 59-63, 2016.

(Yu.A. Stepanova, V.I. Sharobaro, I.P. Kolganova, "Radiation diagnosis of complications of injection breast contouring", Surgery Journal them. N.I. Pirogov, vol. 4, pp. 59-63, 2016.)

22. T. Wong et al., "Magnetic resonance imaging of breast augmentation: a pictorial review", Insights into Imaging, vol. 7, no. 3, pp. 399-410, 2016. https://doi.org/10.1007/s13244-016-0482-9

23. И.Г. Мариничева, "Контурная пластика нижних конечностей”, докторская диссертация, Российский национальный исследовательский медицинский университет имени Н. И. Пирогова, Москва, Россия, 2019.

(I.G. Marinicheva, "Contouring of the lower extremities", Ph.D. dissertation, Pirogov Russian National Research Medical University, Moscow, Russia, 2019.) 